\title{
Copper(II)-selective chelation improves function and antioxidant defences in cardiovascular tissues of rats as a model of diabetes: comparisons between triethylenetetramine and three less copper-selective transition-metal-targeted treatments
}

\author{
J. Lu • D. Gong • S. Y. Choong • H. Xu • Y-K. Chan • X. Chen • S. Fitzpatrick • \\ S. Glyn-Jones $\cdot$ S. Zhang $\cdot$ T. Nakamura $\cdot$ K. Ruggiero $\cdot$ V. Obolonkin $\cdot$ S. D. Poppitt \\ A. R. J. Phillips • G. J. S. Cooper
}

Received: 24 November 2009 / Accepted: 22 January 2010 /Published online: 11 March 2010

(C) Springer-Verlag 2010

\begin{abstract}
Aims/hypothesis Treatment with the $\mathrm{Cu}(\mathrm{II})$-selective chelator triethylenetetramine (TETA) improves cardiovascular disease in human patients, and cardiac and vascular/renal disease in rats used as a model of diabetes. Here we tested two hypotheses: first, that TETA elicits greater improvement in organ function than less $\mathrm{Cu}$-selective transition-metal-targeted treatments; second, that the therapeutic actions of TETA are consistent with mediation through suppression of oxidative stress.
\end{abstract}

Electronic supplementary material The online version of this article (doi:10.1007/s00125-010-1698-8) contains supplementary material, which is available to authorised users.

J. Lu $\cdot$ D. Gong $\cdot$ S. Y. Choong $\cdot$ Y.-K. Chan $\cdot$ X. Chen $\cdot$

S. Fitzpatrick $\cdot$ S. Glyn-Jones $\cdot$ S. Zhang $\cdot$ K. Ruggiero $\cdot$

V. Obolonkin · S. D. Poppitt • A. R. J. Phillips •

G. J. S. Cooper $(\bowtie)$

School of Biological Sciences, Faculty of Science,

University of Auckland, Private Bag,

92019 Auckland, New Zealand

e-mail: g.cooper@auckland.ac.nz

S. Zhang $\cdot$ A. R. J. Phillips $\cdot$ G. J. S. Cooper

The Maurice Wilkins Centre for Molecular Biodiscovery,

Faculty of Science,

University of Auckland, Auckland, New Zealand

\section{A. R. J. Phillips}

Department of Surgery, Faculty of Medical and Health Sciences,

University of Auckland, Auckland, New Zealand

S. D. Poppitt

Department of Medicine, Faculty of Medical and Health Sciences,

University of Auckland, Auckland, New Zealand
Methods Rats were made diabetic with streptozotocin $(55 \mathrm{mg} / \mathrm{kg}$, i. v.) and treated from 8 weeks after disease induction for the following 8 weeks with effective dosages of oral TETA, or one of three less Cu-selective transitionmetal-targeted treatments: D-penicillamine, deferiprone or $\mathrm{Zn}$ acetate. Treatment effects were measured in ex vivo cardiac and aortic tissues, plasma and urine.

Results Diabetes damaged both cardiac and renal/vascular function by impairing the ability of cardiac output to respond physiologically to rising afterload, and by significantly elevat-

Y.-K. Chan · S. D. Poppitt

Human Nutrition Unit, University of Auckland, Auckland, New Zealand

J. $\mathrm{Lu}$

National Centre for Interprofessional Education and Collaborative

Practice, Faculty of Health and Environmental Sciences,

Auckland University of Technology,

Auckland, New Zealand

H. Xu

College of Chemistry and Chemical Engineering,

ShenZhen University, ShenZhen, People's Republic of China

T. Nakamura

Department of Pharmacology, Kansai Medical University,

Osaka, Japan

G. J. S. Cooper

Department of Pharmacology, Medical Sciences Division, University of Oxford, Oxford, UK 
ing the urinary albumin/creatinine ratio. Diabetes also lowered total antioxidant potential and heparan sulphate levels in cardiac and arterial tissues, and serum ferroxidase activity, whereas it elevated urinary heparan sulphate excretion. TETA treatment rectified or partially rectified all these defects, whereas the other three experimental treatments were ineffectual. By contrast, none of the four drug treatments lowered diabetes-mediated elevations of plasma glucose or lipid concentrations.

Conclusions/interpretation TETA may limit the cardiac and renal/vascular damage inflicted by diabetes through its actions to reinforce antioxidant defence mechanisms, probably acting through selective chelation of 'looselybound'/chelatable $\mathrm{Cu}(\mathrm{II})$. It may also improve heparan sulphate homeostasis and bolster antioxidant defence by increasing vascular extracellular superoxide dismutase activity. Urinary albumin/creatinine ratio might prove useful for monitoring TETA treatment.

Keywords Chelator - Diabetic arteriopathy - Diabetic cardiomyopathy - Diabetic nephropathy - Divalent copper . Heparan sulphate $\cdot$ Serum ferroxidase $\cdot$ Streptozotocin . TGF- $\beta \cdot$ Total antioxidant potential

$\begin{array}{ll}\text { Abbreviations } \\ \text { Def } & \text { Deferiprone } \\ \text { ECM } & \text { Extracellular matrix } \\ \text { EC-SOD } & \text { Extracellular superoxide dismutase } \\ \text { HDL-C } & \text { HDL-cholesterol } \\ \text { HS } & \text { Heparan sulphate } \\ \text { Pen } & \text { D-penicillamine } \\ \text { ROS } & \text { Reactive oxygen species } \\ \text { STZ } & \text { Streptozotocin } \\ \text { TAOP } & \text { Total antioxidant potential } \\ \text { TETA } & \text { Triethylenetetramine } \\ \text { uACR } & \text { Urinary albumin/creatinine ratio } \\ \text { ZnA } & \text { Zinc acetate }\end{array}$

\section{Introduction}

Triethylenetetramine (TETA) is a potent and highly selective $\mathrm{Cu}$ (II) chelator [1]. It is an orphan drug used in the treatment of the Wilson's disease [2] and has also shown beneficial effects in the experimental treatment of cardiac/vascular and renal disease in diabetes [3-7]. TETA treatment promotes urinary $\mathrm{Cu}(\mathrm{II})$ excretion in diabetic rats with streptozotocin (STZ)-induced diabetes and patients with type 2 diabetes, and restores cardiac structure and function in both $[3,5]$. However, how TETA improves damaged tissues in diabetes remains unclear.

TETA has been used for the treatment of Wilson's disease for more than two decades. Other compounds that are also used for the treatment of this disease include Dpenicillamine (Pen, a less specific transition-metal chelator) $[2,8]$ and $\mathrm{Zn}$ acetate $(\mathrm{ZnA}$, a blocker of enteric $\mathrm{Cu}$ absorption) [9, 10]. Deferiprone (Def), an orally active Fe chelator that also binds $\mathrm{Cu}$, has also been proposed for this purpose [11, 12]. Whether these compounds might cause similar biochemical changes and improve cardiac and renal function, as TETA does in diabetic rats, remains to be determined.

Several tissue and circulatory variables can yield information concerning cardiovascular risk. Unbound $\mathrm{Cu}$ (II) is strongly pro-oxidant in mammalian tissues [13] and may activate pathways that promote excessive generation of reactive oxygen species (ROS), such as the superoxide anion or hydroxyl radical [13]. Cardiac and arterial superoxide production is increased in animals and humans with diabetes or heart failure [14-16].

Extracellular superoxide dismutase (EC-SOD or SOD3) provides a major antioxidant defence mechanism in mammalian tissues [17], where it is thought to play a major role in the protection of vascular NO from inactivation by superoxide anion [18]. Arterial tissue-bound EC-SOD is decreased in diabetic individuals, promoting increased susceptibility to superoxide-mediated damage via NO depletion and endothelial dysfunction [19]. Elevation of plasma EC-SOD in patients with type 2 diabetes is strongly correlated with an interaction between plasma $\mathrm{HbA}_{1 \mathrm{c}}$ and total $\mathrm{Cu}$ levels [1]. Furthermore, high concentrations of $\mathrm{Cu}(\mathrm{II})$ suppress EC-SOD secretion from cultured vascular smooth muscle cells [20]. The extracellular content of EC-SOD in arterial tissue is associated with the level of heparan sulphate (HS), through which it is bound [21]. Diabetes tends to decrease artery-bound HS [22] and to compromise its function via structural modification [23]. Fibulin-5 is another recently identified EC-SOD-binding anchor in the extracellular matrix (ECM) [24], with cardiac levels reported to be negatively associated with those of $\mathrm{Cu}[25]$.

TGF- $\beta 1$ stimulates ECM protein accumulation in diabetic tissues by upregulating expression of corresponding genes or downregulating genes encoding ECM-degrading enzymes [26]. There is evidence for links between oxidative stress, TGF- $\beta 1$ levels and ECM levels [27]. Excessive accumulation of ECM proteins and associated myocardial fibrosis are implicated as pathogenic mechanisms in diabetic heart disease [28]. Increased fibrous ECM proteins provide the excess $\mathrm{Cu}$-binding sites responsible for the accumulation of elevated loosely bound/chelatable $\mathrm{Cu}(\mathrm{II})$ in diabetes [1, 3, 29]. In a rat model of diabetic complications TETA treatment normalised cardiac and aortic fibrosis, and suppressed elevations of aortic and renal TGF- $\beta 1$ production and urinary albumin/creatinine ratio (uACR) [3, 4, 30]. 
Here, we tested the hypothesis that TETA-mediated improvement in cardiac, arterial and renal tissues damaged by diabetes is dependent on its highly selective binding of $\mathrm{Cu}$ (II). We compared responses to TETA treatment with those to Pen, Def and $\mathrm{ZnA}$, and measured biochemical changes in cardiac and arterial tissues, plasma and urine caused by diabetes and the drug treatments in a wellcharacterised rat model of diabetic complications.

\section{Methods}

Diabetes and drug treatments All studies were approved by relevant ethics and regulatory committees. Male Wistar rats (220-250 g; Integrated Physiology Unit, School of Biological Sciences, University of Auckland, Auckland, New Zealand) were made diabetic by a single intravenous tail-vein injection of STZ (Fluka [St. Louis, MO, USA]; $55 \mathrm{mg} / \mathrm{kg}$ bodyweight) in isotonic saline, as described by Cooper et al. [3]. Agematched control rats were injected with equal volumes of saline (untreated non-diabetic controls: sham). Bodyweight and blood glucose were monitored weekly for 16 weeks.

Rats were housed under conditions of $12 \mathrm{~h}$ light-dark cycle; temperature $22.5^{\circ} \mathrm{C}$ (range $20-26^{\circ} \mathrm{C}$ ); humidity $60 \%$ (range 50-70\%) in like-pairs with ad libitum access to food (Teklad Diet No. 2018; Harlan Laboratories, Indianapolis, IN, USA) and water.

Research questions were addressed in three separate studies. In each, diabetes was not treated for the first 8 weeks after onset, and experimental drug treatments were administered throughout the following 8 week period. The numbers of rats assigned to each treatment were as stated below for the individual studies. Dosages of TETA were based on those found to be efficacious in diabetic rats and patients [1-5]. Dosages of Pen, Def and ZnA were equivalent to those reported to be efficacious in animals and patients, and drug dosing was verified by measurement of disappearance of the drinking water in all studies. In a prior pilot study, the dose of ZnA used was shown to be the maximum tolerated without animals lowering their water intake. All drugs were continuously administered via the drinking water for 8 consecutive weeks.

In study 1, 8 weeks after STZ or saline injection, rats $(n=$ 117) were assigned to one of four groups: (1) sham $(n=28)$; (2) sham-TETA $(n=30)$; (3) STZ $(n=29)$; and (4) STZTETA $(n=30)$. TETA $\left(10 \mathrm{mg}\right.$ day $\left.^{-1} \mathrm{rat}^{-1}\right)$ was administered in the drinking water $(18 \mathrm{M} \Omega / \mathrm{cm}$; Milli Q, Millipore, Billerica, MA, USA) as TETA dihydrochloride (trientine, Fluka), or the equivalent molar dosage of TETA disuccinate [31] (Carbogen, Hunzenschwil, Switzerland) for a further 8 weeks.

In study 2 , rats $(n=113)$ were assigned to one of six groups: (1) sham ( $n=23)$; (2) STZ $(n=26)$; (3) STZ-TETA
$20 \mathrm{mg} /$ day per rat $(n=23)$ [3-5]; (4) STZ-Def (ACROS, Geel, Belgium; $20 \mathrm{mg} /$ day per rat, $n=15$ ) [11, 12]; (5) STZPen (Sigma; St. Louis, MO, USA; $6 \mathrm{mg} /$ day per rat, $n=15$ ) $[2,8]$; and (6) STZ-ZnA (Sigma; $0.5 \mathrm{mg} \mathrm{day}^{-1} \mathrm{rat}^{-1}, n=11$ ) $[9,10]$. A spot urine sample was collected from the bladder of each rat immediately before final tissue collection.

In study 3 , rats $(n=135)$ were assigned to one of ten groups: (1) sham $(n=22)$; (2) sham-TETA $2 \mathrm{mg}$ /day per rat $(n=6)$; (3) sham-TETA $10 \mathrm{mg} /$ day per rat $(n=6)$; (4) shamTETA $20 \mathrm{mg} /$ day per rat $(n=6)$; (5) sham-TETA $50 \mathrm{mg} /$ day per rat $(n=6)$; (6) STZ $(n=26)$; (7) STZ-TETA $2 \mathrm{mg} /$ day per rat $(n=7)$; (8) STZ-TETA $10 \mathrm{mg}$ /day per rat $(n=15)$; (9) STZ-TETA $20 \mathrm{mg} /$ day per rat $(n=22)$; and (10) STZ-TETA $50 \mathrm{mg} /$ day per rat $(n=19)$. Rats were placed individually in metabolism cages for 1 day during each of weeks 10 and $15 ; 24 \mathrm{~h}$ urine samples were collected in propylene tubes and stored at $-80^{\circ} \mathrm{C}$ until assayed.

Isolated perfused working rat heart model Measurements of cardiac function were performed as previously described using this ex vivo approach $[3,4]$ in hearts excised at week 16 from members of the following treatment groups: sham control; untreated diabetic; TETA-treated diabetic $(20 \mathrm{mg} /$ day per rat); Def-treated diabetic (20 mg/day per rat); Pentreated diabetic $(6 \mathrm{mg} /$ day per rat); and $\mathrm{ZnA}$-treated diabetic $(0.5 \mathrm{mg} /$ day per rat). The numbers in each group are as shown in Electronic Supplementary Material (ESM) Table 1.

Tissue collection and treatment In all studies, rats were anaesthetised (halothane, 5\% [vol./vol.]) and organs excised at the end of week 16. Blood samples were collected before heparin injection, and sera were separated by centrifugation and stored at $-80^{\circ} \mathrm{C}$ until assay. Aortic and cardiac tissues were either perfused or washed free of blood with ice-cold PBS. Tissues were stored at $-80^{\circ} \mathrm{C}$ until assay.

Human urine collection Urine samples were collected during a previously reported clinical study [1, 32]. Six healthy male volunteers and seven men with type 2 diabetes (aged between 30 and 70 years) completed that study. Those with diabetic nephropathy/impaired renal function as per serum creatinine $>110 \mu \mathrm{mol} / \mathrm{l}$ and urinary albumin $>300 \mathrm{mg} / \mathrm{l}$ were excluded from the latter group [1]. For each participant, $24 \mathrm{~h}$ urine samples were collected in pre-cleaned wide-mouthed plastic containers (Nuplex Industries, Auckland, New Zealand). Gross urine volumes were recorded and completeness of collections was verified using a $p$-aminobenzoic acid test.

Isolated-perfused working rat heart model In study 2, measurements of cardiac function were performed at the end of week 16, using an ex vivo isolated perfused working-ratheart model $(n=113)$, as previously described [3]. 


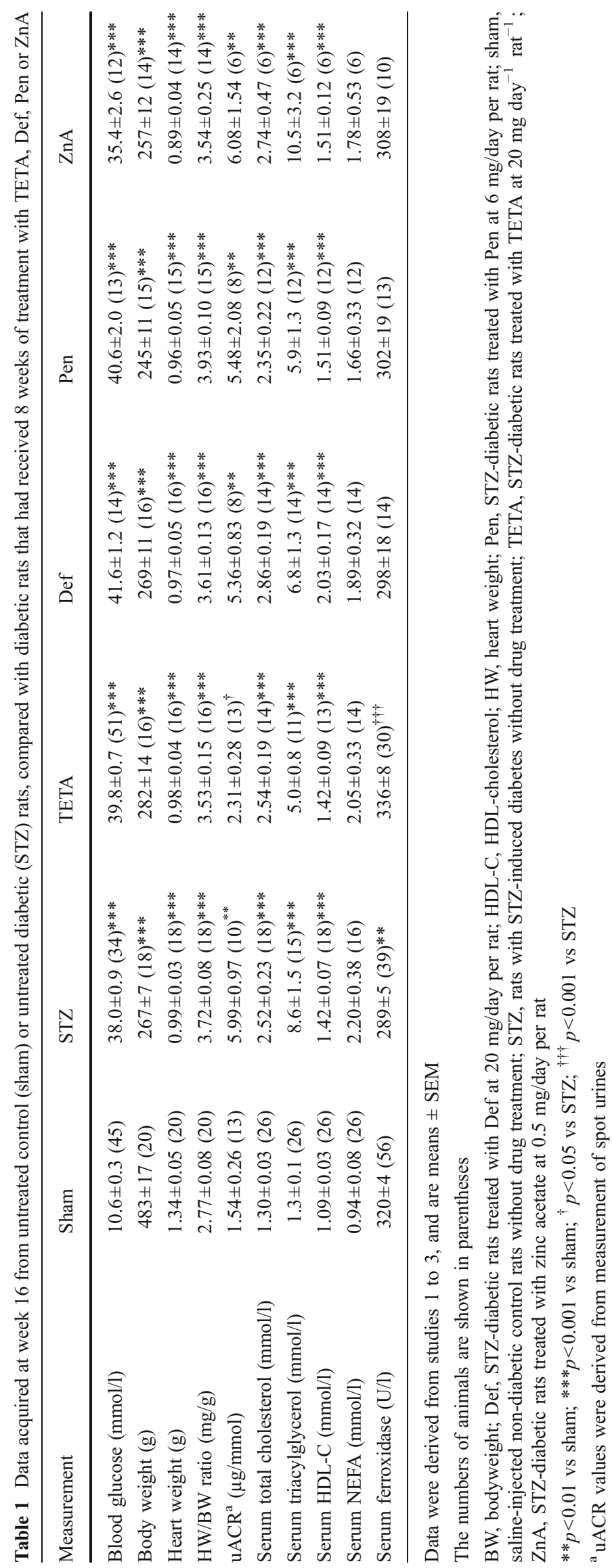


ELISAs for HS, TGF- $\beta 1$ and TNF- $\alpha$ Urinary HS levels from study 3 , and serum, cardiac and aortic tissue samples from study 1 were assayed by ELISA (Seikagaku, Tokyo, Japan) as described [4]. Briefly, frozen cardiac or aortic tissue was homogenised in ice-cold PBS and centrifuged at $13,000 \times \mathrm{g}$ for $20 \mathrm{~min}$ at $4^{\circ} \mathrm{C}$; supernatant fractions were isolated and protein concentrations determined. Then $10 \mu \mathrm{l}$ of $20 \mathrm{mg} / \mathrm{ml}$ actinase E (Kaken Pharmaceuticals, Tokyo, Japan) was added to $100 \mu \mathrm{l}$ supernatant fraction or serum and incubated at $55^{\circ} \mathrm{C}$ for $20 \mathrm{~h}$ to digest tissue and release bound heparan sulphate from proteins. After incubation, samples were boiled for $5 \mathrm{~min}$, cooled and centrifuged at $3,000 \times g$ for $10 \mathrm{~min}$. Processed serum, cardiac and aortic tissue, and untreated urine samples were then assayed according to the manufacturer's instructions in 96-well plates (450 nm; SpectraMax 340, Molecular Devices, Sunnyvale, CA, USA). The HS content in tissue was expressed as $\mu \mathrm{g} / \mathrm{mg}$ protein.

The levels of the active form of TGF- $\beta 1$ in cardiac and aortic tissue from study 1 were determined using the TGF$\beta 1$ Emax ImmunoAssay System (Promega, Madison, WI, USA). The optical density at $450 \mathrm{~nm}$ was measured and the amount of active TGF- $\beta 1$ was expressed as $\mathrm{pg} / \mathrm{mg}$ protein.

TNF- $\alpha$ levels in serum, cardiac and aortic tissue from study 1 were assayed using an Endogen rat TNF- $\alpha$ ELISA kit (Pierce Biotechnology, IL, USA) in 96-well plates (450 nm); TNF- $\alpha$ concentrations have been expressed as $\mathrm{pg} / \mathrm{ml}$ in serum, and $\mathrm{pg} / \mathrm{mg}$ protein in cardiac and aortic tissues.

Biochemical analyses Cardiac and aortic tissues were analysed for TNF- $\alpha$, TGF- $\beta 1$, fibulin-5, total antioxidant potential (TAOP) and HS in study 1 . Urine samples were analysed for HS in study 3; for creatinine at weeks 10 and 15 in study 2, and at week 16 in study 3; and for albumin at week 15 in study 2, and at week 16 in study 3 , and uACR values calculated. Serum from endpoint sampling (week 16) was analysed for glucose, total cholesterol, HDLcholesterol, triacylglycerol, NEFA and ferroxidase in all studies; and for serum levels of Fe, total protein, alkaline phosphatase, aspartate aminotransferase, alanine aminotransferase, bilirubin, calcium and phosphate using standard biochemical methods implemented with a Synchron CX5 (Beckman, Brea, CA, USA).

Urinary albumin was determined using the rat Albumin Enzyme Immunoassay kit (SPI-BIO, Québec, QC, Canada) and urinary creatinine by an enzymatic rate method on the Synchron CX5.

Tissue TAOP assay Supernatant fractions from cardiac and aortic tissue homogenates from study 1 were assayed for total antioxidant potential using an AOP-490 colorimetric kit (OxisResearch, Beverly Hills, CA, USA). This method is based on the reduction of $\mathrm{Cu}$ (II) to $\mathrm{Cu}$ (I) by the combined action of antioxidants present in the sample. The TAOP in each sample was expressed as $\mu \mathrm{mol} / \mathrm{l} \mathrm{Cu}$ reducing equivalents/mg tissue protein.

Statistical analysis Data have been expressed as means \pm SE. One- and two-way ANOVAs, followed by post-hoc Tukey's tests, if appropriate, were performed to assess whether differences between groups were statistically significant. Survival curves describing the ability of isolated perfused working hearts to sustain their outputs with increasing afterload pressures were compared using the logrank test (Prism, v4.02). General linear mixed models were fitted to the data from multi-factor experiments involving repeated measurements over time (e.g. urinary HS) using residual maximum likelihood (SAS v9.1 for Windows). Residual analyses were performed to verify that the underlying assumptions of these methods were met, and appropriate transformations were applied as necessary. Tukey-Kramer adjusted $p$ values (for post-hoc pair-wise comparisons) and Bonferroni-Holm adjusted $p$ values (for a priori comparisons of interest) were calculated. In either case, $p<0.05$ was considered significant and the $n$ value indicates the number of replicates in corresponding assays.

\section{Results}

Diabetes and bodyweight Blood glucose concentrations did not differ among groups at the time of STZ injection (data not shown). Hyperglycaemia occurred within 2 days of STZ administration in all experiments and persisted equivalently in both untreated and drug-treated groups of diabetic rats for the duration of the experiment, indicating that none of the treatments decreased blood glucose levels. Endpoint blood glucose measurements were markedly higher than those in sham controls $(p<0.0001$, Table 1) and no differences were detected between diabetic rats among the various treatments $(p>0.05$, Table 1$)$.

The mean bodyweights of different groups of rats were not significantly different at the time of STZ injection (data not shown), but at week 16, the bodyweights of all groups of diabetic rats were significantly lower than those of sham rats $(p<0.001$, Table 1$)$, and the various drug treatments were all without effect on this variable $(p>0.05$, Table 1$)$.

Cardiac mass The heart weights of diabetic rats were significantly lower than those of sham rats $(p<0.001$, Table 1$)$, and did not differ significantly among the treatment groups ( $p>0.05$, Table 1). Heart weight/bodyweight ratios were significantly higher in diabetic groups than in sham controls $(p<0.001$, Table 1), and the experimental drug treatments did not modify these ratios $(p>0.05$, Table 1$)$. 
Response of cardiac output to increasing afterload in ex vivo isolated working hearts All groups of diabetic rats had impaired cardiac function compared with sham rats, as judged by their inability to maintain their cardiac output at physiological levels in the face of increasing afterload pressure (ESM Table 1). Ante mortem treatment with Pen, Def and $\mathrm{ZnA}$ did not significantly improve cardiac function in diabetic rats (all $p>0.05$ ) whereas, by contrast, TETA treatment increased the resistance of cardiac output to the effects of increasing afterload pressure $(p=0.021$ compared with the untreated diabetic control group). The responses to TETA are consistent with previous reports $[3,4]$.

TAOP, HS, fibulin-5, TGF- $\beta 1$ and TNF- $\alpha$ in cardiac and aortic tissues TAOP levels in cardiac and aortic tissues were significantly lower in diabetic rats compared with sham rats $(p<0.001$ in both tissues, Table 2$)$, and 8 weeks' TETA treatment significantly elevated TAOP levels $(p<$ 0.01 in both tissues, Table 2).

TNF- $\alpha$ levels were not significantly changed in either cardiac or aortic tissue of diabetic rats compared with nondiabetic controls, nor were they significantly modified by TETA treatment ( $p>0.05$, Table 2$)$.

TGF- $\beta 1$ levels were higher in cardiac tissue of diabetic than sham rats $(p<0.05$, Table 2$)$ and TETA treatment restored cardiac TGF- $\beta 1$ protein production to normal $(p<$ 0.05 , Table 2). There was no significant difference in TGF$\beta 1$ protein levels in aortic tissue between rats with or without diabetes or following drug treatment (data not shown).

Fibulin-5 levels in cardiac tissue were insufficient for detection by western blotting, whereas in aortic tissue there was no detectable difference between sham and diabetic rats, or between diabetic rats with and without TETA treatment (Table 2), possibly due to low numbers of replicates.

HS levels in cardiac and aortic tissues were also significantly lower in diabetic rats than in sham controls $(p<0.001$ in both tissues; Table 2). TETA treatment significantly attenuated the diabetes-induced reduction of HS levels in both tissues of diabetic rats $(p<0.05$ in heart and $p<0.01$ in aortic tissues, Table 2).

Urinary $H S$ excretion in rats Urinary HS levels were measured in the $20 \mathrm{mg}$ /day and $50 \mathrm{mg}$ /day dosage groups. Diabetic rats had significantly greater $24 \mathrm{~h}$ urinary HS excretion than matched controls at weeks 10 and 15 (both $p<0.0001$, Table 2). Two weeks' TETA treatment at these dosages did not modify urinary HS excretion (week 10, both $p>0.05$, Table 2). By contrast, following 7 weeks' daily TETA treatment, both dosages did significantly lower $24 \mathrm{~h}$ urinary HS excretion (week 15, $p<0.05$ at $20 \mathrm{mg}$ /day per rat; $p<0.01,50 \mathrm{mg}$ /day per rat; Table 2), consistent with a dosage-dependent effect.

Urinary albumin/creatinine ratios Urinary ACR values in spot urine samples were higher in diabetic rats than sham controls $(p<0.01$, Table 1$)$, as were those measured in $24 \mathrm{~h}$ urine samples $(p<0.01$, Table 2$)$, and TETA treatment significantly lowered the elevated uACR values in both studies $(p<0.05$ in each, Tables 1,2$)$. By contrast, Pen, Def and $\mathrm{ZnA}$ treatments were all without effect on uACR in diabetic rats $(p>0.05$, Table 1$)$.

$H S$ in human urine There was a significant elevation in $24 \mathrm{~h}$ urinary HS excretion in patients with type 2 diabetes compared with healthy volunteers ( $p<0.05$, Fig. 1).

Biochemical variables in serum Serum HS levels were significantly higher in diabetic rats than sham controls $(p<$ 0.05 , Table 2 ) and were not significantly modified by TETA treatment ( $p>0.05$, Table 2).

Urinary HS excretion was positively correlated with serum HS levels (Pearson's correlation analysis; $r^{2}=$ $0.72, n=34 ; p<0.001)$. Mean TNF- $\alpha$ tended to be higher in both diabetic groups, but the difference was not significant and TETA treatment was without effect (both $p>0.05$, Table 2).

Cholesterol, HDL-cholesterol, triacylglycerol, NEFA and ferroxidase were measured in all three studies. Serum cholesterol, HDL-cholesterol and triacylglycerol levels were higher in diabetic rats than in sham controls (all $p<$ 0.001 , Table 1). None of the transition-metal-targeted therapies, including TETA at various dosages, Pen, Def or ZnA significantly altered the serum cholesterol, triacylglycerol or HDL-cholesterol levels in diabetic rats (all $p>0.05$, Table 1). NEFA levels did not differ significantly between sham and diabetic rats, nor did levels change with TETA treatment (all $p>0.05$, Table 1).

Serum ferroxidase activity was significantly lower in diabetic rats than in sham controls $(p<0.01$, Tables 1,2$)$, and all dosages of TETA studied increased values in diabetic rats $(p<0.05,0.001,0.01$ and 0.05 for dosages of $2,10,20$, and $50 \mathrm{mg}$ day $^{-1}$ rat $^{-1}$, respectively, Table 2). By contrast, treatment with Pen, Def or ZnA did not alter serum ferroxidase activity in diabetic rats (all $p>0.05$, Table 1 ), but in that study TETA treatment $(20 \mathrm{mg}$ /day per rat) increased the serum ferroxidase activity significantly $(p<0.001$, Table 1$)$.

The serum values of total protein, alkaline phosphatase, aspartate aminotransferase, alanine aminotransferase, bilirubin, Fe, calcium and phosphate did not differ significantly between sham and diabetic rats, nor did they show significant differences between diabetic rats with TETA treatment at different dosages and untreated diabetic rats (all $p>0.05$, data not shown). 


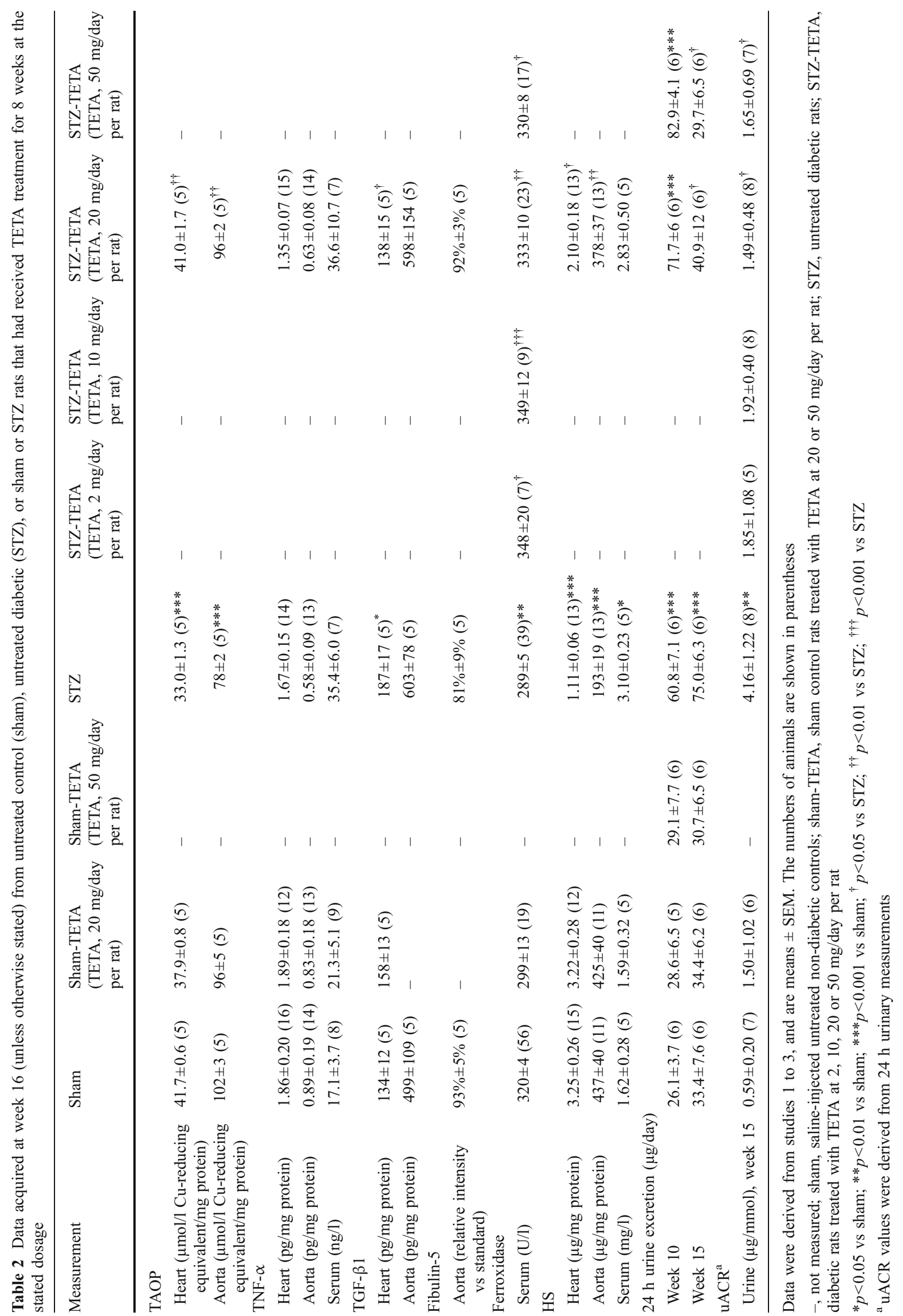




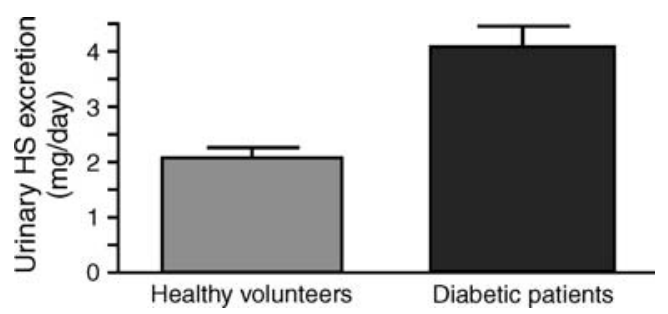

Fig. 1 Twenty-four hour urinary HS excretion values from six healthy volunteers and seven patients with type 2 diabetes. $p<0.05$ for healthy volunteers vs diabetic patients

\section{Discussion}

Oxidative stress has been defined as 'a disturbance in the prooxidant-antioxidant balance in favour of the former' [33]. Elevations in oxidative stress and of 'pro-inflammatory' cytokines such as TGF- $\beta$ and TNF- $\alpha$ have been implicated in the mechanisms of diabetic cardiac, vascular and renal complications [30, 33-38].

To test the hypotheses that TETA elicits greater improvement in organ function than less $\mathrm{Cu}$-selective transition-metal-targeted treatments, and that its therapeutic actions are consistent with mediation through suppression of oxidative stress, we measured the following (methods in parentheses): cardiac function (resistance to rising afterload in an ex vivo perfused working-heart model); renal/vascular damage (uACR); oxidative stress (tissue TAOP, serum ferroxidase, and indices of HS metabolism-the last because HS serves as a main vascular anchor for the antioxidant enzyme EC-SOD); pro-inflammatory cytokines (TGF- $\beta$ and TNF- $\alpha$ ); and widely used traditional biochemical markers of cardiovascular risk (serum levels of total cholesterol and HDL-cholesterol, triacylglycerol and NEFA). We also measured other biochemical indices of liver function, and plasma calcium and phosphate.

Here, TETA treatment partially restored cardiac function whereas transition-metal-targeted but non- $\mathrm{Cu}$ (II)-selective treatments, including Pen, Def and $\mathrm{ZnA}$, did not. These findings are consistent with a hypothesis that TETAmediated improvement in cardiac function is related to its $\mathrm{Cu}$ (II)-selective binding properties.

In patients with type 2 diabetes, elevated circulating ECSOD levels (consistent with lowered SOD activity and impaired defence against superoxide anion-mediated oxidative stress in arterial walls), were reportedly normalised by TETA treatment [1]. HS serves as a major anchor for this important antioxidant defence enzyme [21, 24], binding and localising it in the vascular ECM where it catalyses the elimination of superoxide anion and sustains NO bioavailability [39]. TGF- $\beta 1$ elicits stimulation of collagen production and may play a pivotal role in ECM fibrosis [40]; and $\mathrm{TNF}-\alpha$ is a pro-inflammatory cytokine linked with cardiac disease that is reportedly elevated in cardiovascular tissue compromised by diabetes [41-43].

We found that TETA treatment reversed diabetic tissue damage, as indicated by the following: in the heart (by partially restoring its ability to withstand increasing afterload pressure); renal/vascular damage (by restoring uACR values); oxidative stress (by restoring cardiovascular TAOP, serum ferroxidase, and relevant indices of HS metabolism); and cytokine levels (by lowering diabetes-elevated cardiac TGF- $\beta$ ). TETA did not, however, modify levels of TNF- $\alpha$ or classic biochemical markers of cardiovascular risk (serum lipids), and is thus unlikely to restore cardiovascular structure/function through effects on TNF- $\alpha$.

By contrast, the three other, less $\mathrm{Cu}(\mathrm{II})$-selective, transition-metal-targeted therapies were without impact on any of the measured indices of the diabetic complications. The lack of response to deferiprone is particularly significant, as it supports the conclusion that it is dysregulation of $\mathrm{Cu}$ and not of $\mathrm{Fe}$ homeostasis that plays a key role in the aetiopathogenesis of the diabetic complications [3].

In diabetic rats increased arterial HS was inversely related to urinary HS excretion and blood HS concentration, and these two variables were positively correlated. Treatment with TETA for 7 weeks lowered urinary HS excretion, whereas 2 weeks' treatment did not. Diabetic patients also had significantly higher rates of urinary HS excretion than normal volunteers. However, others have reported that urinary HS values fall in patients with diabetic nephropathy [44], and it is possible that some of our observations concerning HS in rats might have been confounded by STZ-mediated toxicity. The much lower HS concentrations in cardiac compared with aortic tissue suggests that cardiac HS levels could reflect those in the coronary artery walls, so increased HS following TETA treatment could point to improved coronary artery function. These data are also consistent with our prior finding that TETA treatment elevated the depressed aortic wall EC-SOD in diabetic rats [4]. Based on these observations, urinary HS merits further investigation as a variable for monitoring therapeutic responses to TETA.

Caeruloplasmin catalyses the oxidation of $\mathrm{Fe}$ (II) to $\mathrm{Fe}(\mathrm{III})$ through its action as a ferroxidase, and thereby facilitates loading of $\mathrm{Fe}$ into transferrin without the concomitant generation of superoxide anions and hydroxyl radicals that could otherwise ensue [33]. Diabetes-mediated lowering of ferroxidase activity could undermine this antioxidant effect, so restoration of serum ferroxidase by TETA points to its bolstering of this diabetes-compromised defence mechanism. TAOP provides a plausible measure of oxidative stress in cardiovascular tissues [45-48]. However, the accurate assessment of oxidative stress in biological systems is a problem for all investigators working on the role of free radical damage in disease [33, 48]. Low total 
antioxidant capacity can be interpreted as indicative of oxidative stress or increased susceptibility to oxidative damage. However, measurements of TAOP, such as that we employed here, have limitations [48]. Most assays tend to measure predominantly the antioxidants with lower molecular mass, such as urate, ascorbate, bilirubin, and thiols in the aqueous phase, and $\alpha$-tocopherol, carotenoids, and flavonoids in the lipid phase, excluding the contribution of antioxidant enzymes and metal-binding proteins; different approaches to the measurement of TAOP correlate poorly with one another [48]. In most biological fluids, the major contributor in such assays is urate, which frequently accounts for more than $50 \%$ of the total antioxidant potential measured. However, urate is of limited importance as an antioxidant in vivo, and a preferable approach would be to measure all potential antioxidants [48]. Such studies will need to be performed in future, to more accurately judge the antioxidant mechanisms by which $\mathrm{Cu}(\mathrm{II})$-selective chelation elevates TAOP.

We conclude that dysregulation of $\mathrm{Cu}$, but not of $\mathrm{Fe}$, homeostasis is a key pathogenic mechanism in the diabetic complications. These data are consistent with the hypothesis that raised $\mathrm{Cu}$ (II)-evoked oxidative stress is causative of the complications of diabetes. TETA treatment may limit the cardiac and renal/vascular damage caused by diabetes through its actions to bolster antioxidant defences, and its $\mathrm{Cu}(\mathrm{II})$ selective binding ability probably plays a major role in its actions. These findings are consistent with our previous description of pathogenic dysregulation of $\mathrm{Cu}$ homeostasis as a major contributor to the mechanisms of diabetes-evoked cardiac and renal/vascular damage, and their improvement following TETA treatment [1]. Urinary ACR, whether derived from $24 \mathrm{~h}$ or spot urinary measurements, could be useful for monitoring TETA treatment. Further investigation of the mechanisms by which $\mathrm{Cu}$ (II)selective chelators abrogate tissue damage in diabetes is warranted.

Acknowledgements This study was funded by grants from the Endocore Research Foundation (G. J. S. Cooper), the Foundation for Research, Science and Technology, New Zealand (G. J. S. Cooper); the Health Research Council of New Zealand (G. J. S. Cooper); the Maurice and Phyllis Paykel Trust (G. J. S. Cooper and J. Lu); the National Heart Foundation of New Zealand (J. Lu); National Natural Science Foundation of China (H. Xu, grant 30570421); Auckland Medical Research Foundation (J. Lu and D. Gong); the New Zealand Lottery Grants Board (G. J. S. Cooper and D. Gong). We thank C. Tse (School of Biological Sciences, University of Auckland, Auckland, New Zealand) for her contributions to the management of these studies and the development of the manuscript, and V. Tintinger, R. Smith and S. Costa for their technical assistance.

Duality of interest J. Lu, D. Gong, Y. S. Choong, Y. K. Chan, X. Chen, S. Fitzpatrick, S. Glyn-Jones, S. Zhang, S. D. Poppitt, A. R. J. Phillips and G. J. S. Cooper declare past associations with Protemix Corporation, Auckland, New Zealand. All other authors declare that there is no duality of interest associated with this work.

\section{References}

1. Cooper GJS, Chan YK, Dissanayake AM et al (2005) Demonstration of a hyperglycemia-driven pathogenic abnormality of copper homeostasis in diabetes and its reversibility by selective chelation: quantitative comparisons between the biology of copper and eight other nutritionally essential elements in normal and diabetic individuals. Diabetes 54:1468-1476

2. Walshe JM (1973) Copper chelation in patients with Wilson's disease. A comparison of penicillamine and triethylene tetramine dihydrochloride. Q J Med 42:441-452

3. Cooper GJS, Phillips ARJ, Choong SY et al (2004) Regeneration of the heart in diabetes by selective copper chelation. Diabetes 53:2501-2508

4. Gong D, Lu J, Chen X et al (2006) Molecular changes evoked by triethylenetetramine (TETA) treatment in the extracellular matrix of the heart and aorta in diabetic rats. Mol Pharmacol 70:2045-2051

5. Cooper GJS, Young AA, Gamble GD et al (2009) A copper(II)selective chelator ameliorates left-ventricular hypertrophy in type-2 diabetic patients. Diabetologia 52:715-722

6. Baynes JW, Murray DB (2009) The metal chelators, trientine and citrate, inhibit the development of cardiac pathology in the Zucker diabetic rat. Exp Diabetes Res 2009:696378

7. Gong D, Chen X, Middleditch M et al (2009) Quantitative proteomic profiling identifies new renal targets of copper(II)selective chelation in the reversal of diabetic nephropathy in rats. Proteomics 9:4309-4320

8. Joyce DA (1990) D-penicillamine. Baillières Clin Rheumatol $4: 553-574$

9. Anderson LA, Hakojarvi SL, Boudreaux SK (1998) Zinc acetate treatment in Wilson's disease. Ann Pharmacother 32:78-87

10. Brewer GJ (2001) Zinc acetate for the treatment of Wilson's disease. Expert Opin Pharmacother 2:1473-1477

11. Kontoghiorghes GJ, Pattichis K, Neocleous K, Kolnagou A (2004) The design and development of deferiprone (L1) and other iron chelators for clinical use: targeting methods and application prospects. Curr Med Chem 11:2161-2183

12. Piga A, Roggero S, Vinciguerra T, Sacchetti L, Gallo V, Longo F (2005) Deferiprone: new insight. Ann N Y Acad Sci 1054:169174

13. Fraústo da Silva JJ, Williams RJ (2001) The biological chemistry of the elements: the inorganic chemistry of life. Clarendon, Oxford, pp 418-435

14. Kojda G, Harrison D (1999) Interactions between NO and reactive oxygen species: pathophysiological importance in atherosclerosis, hypertension, diabetes and heart failure. Cardiovasc Res 43:562571

15. Guzik T, Mussa S, Gastaldi D et al (2002) Mechanisms of increased vascular superoxide production in human diabetes mellitus: role of $\mathrm{NAD}(\mathrm{P}) \mathrm{H}$ oxidase and endothelial nitric oxide synthase. Circulation 105:1656-1662

16. Creager MA, Luscher TF, Cosentino F, Beckman JA (2003) Diabetes and vascular disease: pathophysiology, clinical consequences, and medical therapy: Part I. Circulation 108:1527-1532

17. Marklund SL (1984) Extracellular superoxide dismutase in human tissues and human cell lines. J Clin Invest 74:1398-1403

18. Oury TD, Day BJ, Crapo JD (1996) Extracellular superoxide dismutase: a regulator of nitric oxide bioavailability. Lab Invest 75:617-636

19. Fattman CL, Schaefer LM, Oury TD (2003) Extracellular superoxide dismutase in biology and medicine. Free Radic Biol Med 35:236-256

20. Stralin P, Jacobsson H, Marklund SL (2003) Oxidative stress, NO and smooth muscle cell extracellular superoxide dismutase expression. Biochim Biophys Acta 1619:1-8 
21. Sandstrom J, Karlsson K, Edlund T, Marklund SL (1993) Heparin-affinity patterns and composition of extracellular superoxide dismutase in human plasma and tissues. Biochem $\mathrm{J}$ 294:853-857

22. Edwards IJ, Wagner JD, Vogl-Willis CA, Litwak KN, Cefalu WT (2004) Arterial heparan sulfate is negatively associated with hyperglycemia and atherosclerosis in diabetic monkeys. Cardiovasc Diabetol 3:6

23. Vogl-Willis CA, Edwards IJ (2004) High-glucose-induced structural changes in the heparan sulfate proteoglycan, perlecan, of cultured human aortic endothelial cells. Biochim Biophys Acta 1672:36-45

24. Nguyen AD, Itoh S, Jeney V et al (2004) Fibulin-5 is a novel binding protein for extracellular superoxide dismutase. Circ Res 95:1067-1074

25. Zeng H, Saari JT, Dahlen GM (2006) Copper deficiency increases fibulin-5 (DANCE/EVEC) but decreases cytochrome C oxidase VIb subunit expression in rat heart. J Inorg Biochem 100:186-191

26. Roberts AB, McCune BK, Dunn SR (1992) TGF- $\beta$ : regulation of extracellular matrix. Kidney Int 41:557-559

27. Williams B (1998) Mechanical influences on vascular smooth muscle cell function. J Hypertens 16:1921-1929

28. Marklund SL (1992) Regulation by cytokines of extracellular superoxide dismutase and other superoxide dismutase isoenzymes in fibroblasts. J Biol Chem 267:6696-6701

29. Qian M, Liu M, Eaton JW (1998) Transition metals bind to glycated proteins forming redox active "glycochelates": implications for the pathogenesis of certain diabetic complications. Biochem Biophys Res Commun 250:385-389

30. Gong D, Lu J, Chen X et al (2008) A copper(II)-selective chelator ameliorates diabetes-evoked renal fibrosis and albuminuria, and suppresses pathogenic TGF- $\beta$ activation in the kidneys of rats used as a model of diabetes. Diabetologia 51:1741-1751

31. Wichmann KA, Boyd PDW, Söhnel T, Allen GR, Phillips ARJ, Cooper GJS (2007) Characterization of dicarboxylic salts of protonated triethylenetetramine useful for the treatment of copperrelated pathologies. Cryst Growth Des 7:1844-1850

32. Lu J, Chan Y-K, Poppitt SD, Cooper GJS (2007) Determination of triethylenetetramine (TETA) and its metabolites in human plasma and urine by liquid chromatography-mass spectrometry (LC-MS). J Chromatogr B: Anal Technol Biomed Life Sci 859:62-68

33. Halliwell B, Gutteridge JM (1999) Free radicals in biology and medicine. Oxford University Press, Oxford
34. Martin J, Kelly DJ, Mifsud SA et al (2005) Tranilast attenuates cardiac matrix deposition in experimental diabetes: role of transforming growth factor- $\beta$. Cardiovasc Res 65:694-701

35. Jay D, Hitomi H, Griendling KK (2006) Oxidative stress and diabetic cardiovascular complications. Free Radic Biol Med 40:183-192

36. Haidara MA, Yassin HZ, Rateb M, Ammar H, Zorkani MA (2006) Role of oxidative stress in development of cardiovascular complications in diabetes mellitus. Curr Vasc Pharmacol 4:215-227

37. Stephens JW, Khanolkar MP, Bain SC (2009) The biological relevance and measurement of plasma markers of oxidative stress in diabetes and cardiovascular disease. Atherosclerosis 202:321-329

38. Friederich M, Hansell P, Palm F (2009) Diabetes, oxidative stress, nitric oxide and mitochondria function. Curr Diabetes Rev 5:120-144

39. Marklund SL (2002) Extracellular superoxide dismutase. Methods Enzymol 349:74-80

40. Sharma K, Ziyadeh FN (1995) Hyperglycemia and diabetic kidney disease: the case for transforming growth factor-beta as a key mediator. Diabetes 44:1139-1146

41. Mann DL (2002) Inflammatory mediators and the failing heart: past, present, and the foreseeable future. Circ Res 91:988-998

42. Gullestad L, Kjekshus J, Damas JK, Ueland T, Yndestad A, Aukrust P (2005) Agents targeting inflammation in heart failure. Expert Opin Investig Drugs 14:557-566

43. Kaur K, Sharma AK, Singal PK (2006) Significance of changes in TNF-alpha and IL-10 levels in the progression of heart failure subsequent to myocardial infarction. Am J Physiol Heart Circ Physiol 291:H106-H113

44. Yokoyama H, Sato K, Okudaira M et al (1999) Serum and urinary concentrations of heparan sulfate in patients with diabetic nephropathy. Kidney Int 56:650-658

45. Ghiselli A, Serafini M, Natella F, Scaccini C (2000) Total antioxidant capacity as a tool to assess redox status: critical view and experimental data. Free Radic Biol Med 29:1106-1114

46. Prior RL, Cao G (1999) In vivo total antioxidant capacity: comparison of different analytical methods. Free Radic Biol Med 27:1173-1181

47. Buffon A, Santini SA, Ramazzotti V et al (2000) Large, sustained cardiac lipid peroxidation and reduced antioxidant capacity in the coronary circulation after brief episodes of myocardial ischemia. $\mathrm{J}$ Am Coll Cardiol 35:633-639

48. Young IS (2001) Measurement of total antioxidant capacity. J Clin Pathol 54:339 